\title{
Thermoelectrical Investigation of Rare Earth Sulfide Materials
}

\author{
V. V. Sokolov ${ }^{1}$, V. V. Bakovetz ${ }^{1}$, S. M. Luguev ${ }^{2}$, N. V. Lugueva ${ }^{2}$ \\ ${ }^{1}$ Nikolaev Institute of Inorganic Chemistry SB RAS, NIIC SB RAS, Novosibirsk, Russia \\ ${ }^{2}$ Amirkhanov Institute of Physic DSC RAS, IPh DSC RAS, Makhachkala, Dagestan. Russia \\ Email: sokolov@niic.nsc.ru, luguev.if@mail.ru
}

Received 2012

\begin{abstract}
Results are presented on synthesis and crystal growth of $\mathrm{Gd}_{2} S_{3}-\mathrm{Dy}_{2} S_{3}$ solid solution sulfides and study of their thermoelectric properties in the range of temperatures $80-400 \mathrm{~K}$. Gd ${ }_{0.2} \mathrm{Dy}_{0.8} \mathrm{~S}_{1.48}$ composition has the best values of thermoelectric efficiency $0.39 \mathrm{x}$ $10^{-3} / \mathrm{K}$ at $400 \mathrm{~K}$.
\end{abstract}

Keywords: Gd2S3 - Dy2S3 Solid Solution Sulfides; Synthesis; Growth of Crystals; Thermoelectric Properties

\section{Introduction}

Interest in investigation of rare-earth Ln2S3 sulfides with the structure of Thorium phosphide is bound with possible application of compositions on their base as working elements of thermoelectric energy converters for high temperatures. The researches of GdSy $(1.45 \leqslant \mathrm{y} \leqslant 1.50)[1,2]$ showed that some compositions at $1000 \mathrm{~K}$ have more high thermoelectric efficiency of $\mathrm{Z}$ then Ge-Si solid solution compositions. The structure of Ln2S3 sulfides allows to fill vacancy with rareearth and other metals and to change their thermoelectric properties. To increase thermoelectric efficiency of material it is usual to decrease its thermal conductivity creating there additional centers of phonon scattering. Such centers for the GdSy system may be presented by the doping paramagnetic ions of rare-earth elements scattering phonons and decreasing thermal conductivity but not modifying electrical characteristics of the compound. The research of Gd1-xDyxS1.48 compositions containing paramagnetic Dy ions showed that in this system near Gd0.2Dy0.8S1.48 have the minimum thermal conductivity [3]. Therefore is of interest to study dynamics of thermoelectric properties of these compositions in dependence from temperature. In this work the synthesis, preparation of crystals in Gd2S3 - Dy2S3 system and their thermoelectric properties in the range of temperatures $80-400 \mathrm{~K}$ are presented.

\section{Experimental}

\subsection{Preparation of Gd2S3 and Dy2S3 Sulfides}

Sulfides Gd2S3 and Dy2S3 were prepared from high-purity rare earth oxides (99.95\%) by $\mathrm{H} 2 \mathrm{~S}$ sulfidizing at $950-10000 \mathrm{C}$ [4].

The mixtures of sulfides for crystallization were prepared with 0.1 mol. step.

\subsection{Growth of Gd2S3 - Dy2S3 Solid Solution Crystals}

Directed crystallization from sulfide melts at $1700-2000^{\circ} \mathrm{C}$ in carbon and glass-carbon containers with HF heating was used.

Crystallization of prepared compositions was carried out under inert gas atmosphere for preparation of nonstoichiometric with electron conductivity crystals [5]. Crystallization velocity was $5-30 \mathrm{~mm} / \mathrm{h}$. The diameter of the obtained cylindrical samples of crystals was $10 \mathrm{~mm}$ and height $-10-30 \mathrm{~mm}$.

\subsection{Methods of Characterization of Crystals}

- XRD - parameters of cubic $\mathrm{Th}_{3} \mathrm{P}_{4}$ type

- Gravimetric measurements of density

- Measurements of Seebeck coefficient at $20^{\circ} \mathrm{C}$

- Chemical and gas-chromatografic analysis of composition [6]

\subsection{Study of Thermoelectrical Properties}

To study thermoelectrical properties the samples were cut from the central part of ingots that was the most uniform. At temperature measurements the composition change on sulfur therefore uncertainty in an index at sulfur +-0.01 is possible.

Measurements of thermal conductivity coefficient were performed with absolute stationary method.

The equipment simultaneously with measurement of $\kappa$ in the same samples allowed to measure electrical conductivity and Seebeck coefficient at 80-400 K.

\section{Results and Discussion}

\subsection{Characterization of Prepared Crystals}

Results of characterization of prepared crystals of $\mathrm{Gd}_{2} \mathrm{~S}_{3}$ $\mathrm{Dy}_{2} S_{3}$ solid solution is presented in Table 1.

All crystals have cubic structure of $\mathrm{Th}_{3} \mathrm{P}_{4}$ type with linear dependence of cell parameters from composition.

The same dependence is in density of crystals from composition.

Deviation of composition from stoichiometry from $\mathrm{Gd}_{2} \mathrm{~S}_{3}$ to $\mathrm{Dy}_{2} S_{3}$ agree with their phase diagrams.

Increasing of Seebeck coefficient from $\mathrm{Gd}_{2} \mathrm{~S}_{3}$ to $\mathrm{Dy}_{2} S_{3}$ to 
agree with deviation composition from stoichiometry of crystals.

\subsection{Results of Thermoelectric Measurements}

Temperature dependences of thermal conductivity coefficient in $\mathrm{Gd}_{2} \mathrm{~S}_{3}-\mathrm{Dy}_{2} \mathrm{~S}_{3}$ system for the series of compositions at $80-400$ $\mathrm{K}$ are presented in Figure 1.

$\mathrm{Up}$ to $\mathrm{Gd}_{0.6} \mathrm{Dy}_{0.4} \mathrm{~S}_{1.48}$ thermal conductivity weakly depends on the concentration of Dy ions and $\mathrm{Gd}_{0.2} \mathrm{Dy}_{0.8} \mathrm{~S}_{1.490}$ sample has minimal thermal conductivity in this system (Figure 2).

Analysis of thermal conductivity is made in paper [3]. Substantial decrease of thermal conductivity coefficient is observed for the compositions with $\mathrm{x}>0.6$, and minimal value $\kappa$ - at $\mathrm{x}=0.8$. Such dependence of thermal conductivity coefficient of the samples unusual for phonon heat transfer is results from phonon scattering by paramagnetic ions of Dysprosium.

Results of Seebeck coefficient and electrical conductivity measurements are presented on Figure 3 and 4.

Temperature dependence of Seebeck coefficient and electrical conductivity has the same character that usual metals or doped semiconductors. At constant concentration of carriers of a current and decrease of their mobility with growth of temperature Seebeck coefficient linearly grows and electrical conductivity decreases.

Table 1. Characteristics of crystals in Gd2S3 - Dy2S3 system.

\begin{tabular}{|c|c|c|c|c|c|c|}
\hline \multirow{2}{*}{$\begin{array}{c}\begin{array}{c}\text { Composition } \\
\text { mol. Gd } \mathbf{G S}_{\mathbf{3}}\end{array} \\
1\end{array}$} & \multirow{2}{*}{$\begin{array}{c}\begin{array}{c}\text { Parameter } \\
\text { of cell, } \AA\end{array} \\
8.372\end{array}$} & \multicolumn{2}{|c|}{$\begin{array}{l}\text { Index } y \text { in } \\
\operatorname{Gd}_{1-x} D y_{x} S_{y} \\
\text { exp. calc. }\end{array}$} & \multicolumn{2}{|c|}{$\begin{array}{l}\text { Density d, } \\
\text { g/ } \mathrm{cm}^{3} \\
\text { exp. calc. }\end{array}$} & \multirow{2}{*}{$\begin{array}{c}\text { Seebeck coeff. } \\
\qquad, \mathbf{m k V} / \mathbf{K} \\
62\end{array}$} \\
\hline & & 1.466 & 1.464 & 6.30 & 6.29 & \\
\hline 0.9 & 8.365 & 1.464 & 1.467 & 6.33 & 6.34 & 68 \\
\hline 0.8 & 8.358 & 1.471 & 1.470 & 6.35 & 6.35 & 77 \\
\hline 0.7 & 8.350 & 1.476 & 1.477 & 6.36 & 6.37 & 72 \\
\hline 0.6 & 8.340 & 1.479 & 1.480 & 6.39 & 6.39 & 80 \\
\hline 0.5 & 8.331 & 1.478 & 1.482 & 6.42 & 6.43 & 76 \\
\hline 0.4 & 8.328 & 1.479 & 1.473 & 6.46 & 6.45 & 88 \\
\hline 0.3 & 8.323 & 1.488 & 1.482 & 6.47 & 6.45 & 107 \\
\hline 0.2 & 8.311 & 1.490 & 1.487 & 6.50 & 6.49 & 110 \\
\hline 0.1 & 8.302 & 1.489 & 1.486 & 6.54 & 6.53 & 104 \\
\hline 0 & 8.292 & 1.493 & 1.495 & 6.55 & 6.56 & 125 \\
\hline
\end{tabular}

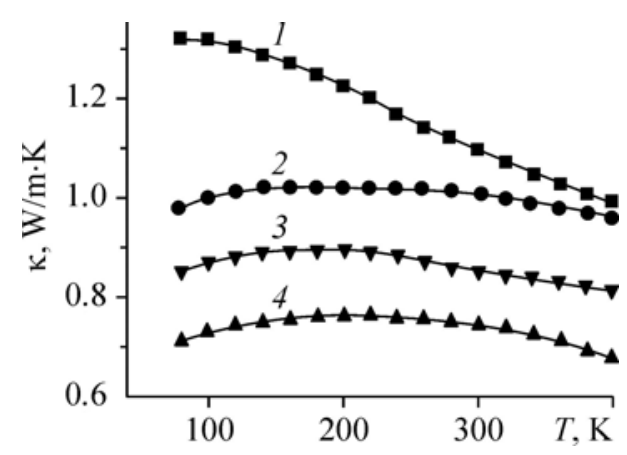

Figure 1. Temperature dependences of thermal conductivity coefficient of $\mathrm{GdS}_{1.48}$ (1), Gd0.6 $\mathrm{Dy}_{0.4} \mathrm{~S}_{1.48}$ (2), DyS $\mathrm{S}_{1.48} \quad$ (3), Gd0.2 $D_{0.8} S_{1.48}$ (4).

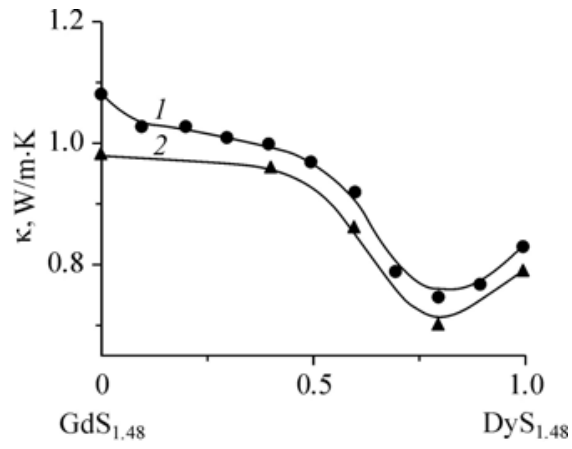

Figure 2. Concentration dependences of thermal conductivity coefficient of solid solutions $\mathrm{Gd}_{1-\mathrm{x}} \mathrm{Dy}_{\mathrm{x}} \mathrm{S}_{1.48}$ at 300 (1) and $400 \mathrm{~K}$ (2).

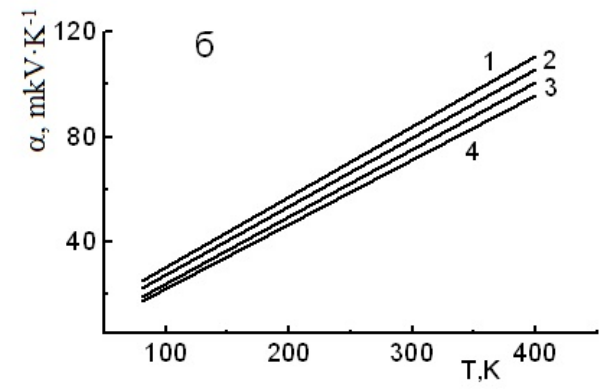

Figure 3. Temperature dependences of Seebeck coefficient of $G_{0.3} D_{0.7} S_{1.48}(1), G_{0.2} D_{0.8} S_{1.48}(2), G_{0.1} D_{0.9} S_{1.48}(3), G d S_{1.48}$ (4).

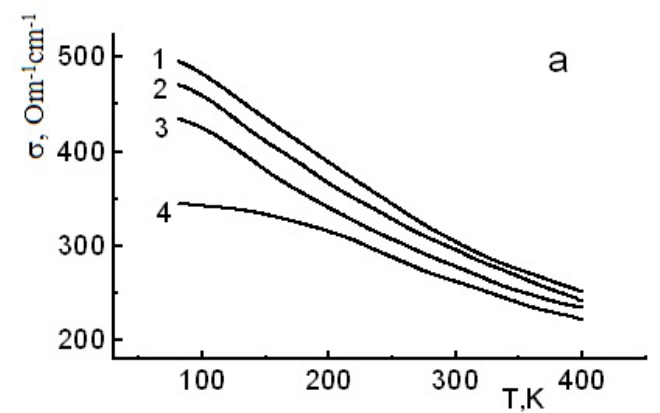

Figure 2. Temperature dependences of electrical conductivity of $G_{d S_{1.48}}(1), G_{0.1} D y_{0.9} S_{1.48}(2), G_{0.2} D y_{0.8} S_{1.48}(3), G_{0.3} D_{0.7} S_{1.48}$ (4).

Replacement of Gadolinium by Dysprosium as it was established earlier [7], at $300 \mathrm{~K}$ changes of Seebeck coefficient growth and electrical conductivity lowering no more than for $18 \%$ within $\mathrm{Gd}_{1-\mathrm{x}} \mathrm{Dy}_{\mathrm{x}} \mathrm{S}_{1.48}$ compositions. At $80 \mathrm{~K}$ electrical conductivity of $\mathrm{Gd}_{0.3} \mathrm{Dy}_{0.7} \mathrm{~S}_{1.48}$ is lower for $30 \%$, than at $\mathrm{GdS}_{1.48}$.

On the basis of experimental data of Seebeck coefficient and electrical and thermal conductivity the thermoelectric efficiency ( $\left.\mathrm{Z}=\alpha^{2} \sigma / \kappa\right)$ of the studied compositions was calculated. $\mathrm{Gd}_{0.2} \mathrm{Dy}_{0.8} \mathrm{~S}_{1.48}$ composition has the best values of this parameter among the samples investigated in this work. Values $\mathrm{Z}$ for the studied samples at 300 and $400 \mathrm{~K}$ are presented in the Table 2.

Thus, study of thermal conductivity, Seebeck coefficient and electrical conductivity of $\mathrm{Gd}_{1-\mathrm{x}} \mathrm{Dy}_{\mathrm{x}} \mathrm{S}_{1.48}$ compositions in a range of temperatures $80-400 \mathrm{~K}$ showed that the main contribution to heat transfer to them is brought by fluctuations of a crystal Table 2. Thermoelectric properties of some $\mathbf{G d}_{1-\mathrm{x}} \mathrm{Dy}_{\mathrm{x}} \mathrm{S}_{1.48}$ 
composition.

\begin{tabular}{|c|c|c|c|c|c|}
\hline Composition & $\begin{array}{c}-\alpha, \\
\mathbf{m k V} \cdot \mathbf{K}^{-1} \\
\mathbf{3 0 0} \mathbf{K}\end{array}$ & $\begin{array}{c}\sigma, \\
\mathrm{Om}^{-1} \mathbf{c m}^{-1} \\
\mathbf{3 0 0} \mathbf{K}\end{array}$ & $\begin{array}{c}\kappa, \\
\mathbf{W} \mathbf{m}^{-1} \mathbf{K}^{-1} \\
300 \mathrm{~K}\end{array}$ & $\begin{array}{c}\mathrm{Z} \cdot 10^{3}, \mathrm{~K}^{-1} \\
\mathbf{3 0 0} \mathrm{K}\end{array}$ & $\begin{array}{c}Z \cdot 10^{3}, K^{-1} \\
400 \mathrm{~K}\end{array}$ \\
\hline $\operatorname{GdS}_{1.48}$ & 72 & 304 & 1.04 & 0.16 & 0.27 \\
\hline $\mathrm{Gd}_{0.3} \mathrm{Dy}_{0.7} \mathrm{~S}_{1.48}$ & 83 & 262 & 0.80 & 0.23 & 0.34 \\
\hline $\mathrm{Gd}_{0.2} \mathrm{Dy}_{0.8} \mathrm{~S}_{1.48}$ & 80 & 278 & 0.74 & 0.24 & 0.39 \\
\hline $\mathrm{Gd}_{0.1} \mathrm{Dy}_{0.9} \mathrm{~S}_{1.48}$ & 75 & 298 & 0.84 & 0.20 & 0.32 \\
\hline
\end{tabular}

lattice. It is established that replacement of atoms of a Gadolinium by Dysprosium reduces thermal conductivity with growth of deficiency of a crystals and additional scattering of phonon on paramagnetic Dy ions. On the basis of experimental data in all studied temperature interval the $\operatorname{Gd}_{0.2} \mathrm{Dy}_{0.8} \mathrm{~S}_{1.48}$ sample has maximal value of thermoelectric efficiency.

\section{REFERENCES}

[1] G.G. Gadzhiev, S.M. Luguev, V.V. Sokolov, B.N. Magdiev.,
N.V. Lugueva. In book.: Transfer of carriers of a charge and heat in semiconductors. Makhachkala, 1986, page 87-93.(on Russian)

[2] S.M. Luguev, V.V. Sokolov, N.V. Lugueva. Advanced Materials and Proceessing. Proceedings of Russia-Japan Seminar, September 15-20, 2007. Novosibirsk, 2007, p. 71-75.

[3] S.M. Luguev, N.V. Lugueva, V.V. Sokolov. Temperature and concentration dependences of thermal conductivity of solid solutions of gadolinium and dysprosium// Thermophysics and Aeromechanics, vol. 19, No. 3, pp. 375-380, 2012.

[4] V.V. Sokolov, A.A. Kamarzin, L.N.Trushnikova, M.V. Savelyeva Optical materials containing rare earth $\mathrm{Ln}_{2} \mathrm{~S}_{3}$ sulfides // J. Alloys and Comp. vol. 225, No. 2,. pp. 567-570, 1995.

[5] A.A. Kamarzin, K.E. Mironov, V.V. Sokolov Growth and Properties of Lanthanum and Rare Earth Metal Sesquisulfide Crystals // J.Crystal Growth. vol. 52, pp. $619-622,1981$.

[6] L.S. Chuchalina, I.G. Vasilyeva, A.A. Kamarzin Non-direct method of gas-chromatografic analysis of determination of lanthanum sulfide composition// Journal of Analytical Chemistry vol. 33, n. 1, pp.190-192, 1978. (on Russian)

[7] S.M. Luguev, N.V. Lugueva, V.V. Sokolov. Thermoelectrics and their applications. Reports of the X-th interstate seminar. , Ioffe PTI, pp.179-183, 2007. (on Russian) 